\title{
Pengaruh Aplikasi Tiga Jenis Arang dan Klon terhadap Pertumbuhan Vegetatif Dan Serapan Unsur Silika (Si) Tebu (Saccharum Officinarum L.) PT. Perkebunan Nusantara $X$ Jengkol Kediri
}

\section{The Effect of Application Three Biochars and Clones on Vegetative Growth and Absorption Silica (Si) Sugarcane (Saccharum Officinarum L.) PT. Perkebunan Nusantara $X$ Jengkol Kediri}

\author{
Priyo Dwi Siswanto ${ }^{1}$, Dody Kastono ${ }^{1^{\star}}$, Nasih Widya Yuwono ${ }^{2)}$ \\ 1) Departemen Budidaya Pertanian, Fakultas Pertanian, Universitas Gadjah Mada \\ 2) Departemen Tanah, Fakultas Pertanian, Universitas Gadjah Mada \\ *) Penulis untuk korespondensi Email: dodykastono@gmail.com
}

\begin{abstract}
Sugarcane (Saccharum officinarum L.) is one of the main commodities in Indonesia which is a sugar producing plant. National sugar production has declined due to low sugarcane productivity. The provision of materials intended to improve the soil conditions of both physics, chemistry and biology is called amendment (amelioration). Natural ingredients that can be used to overcome nutrient deficiency and improve the efficiency of fertilization by charcoal. Sugarcane plants need Si element in its growth. One of the organic materials containing high Si is charcoal. Si content from various sources, Si on rice husk charcoal is the highest. In addition to fertilization factors, clone factors that are suitable for the land are also very important to increase the production of sugarcane. Clones is a step taken to improve the nature of a plant both in terms of qualitative and quantitative. This study aims to determine the combination of the type of charcoal with clones that have the best growth and nutrient uptake. Research done in PT. Perkebunan Nusantara $X$ Jengkol Kediri using Randomized Completely Block Design (RCBD) with two factors. The first factor is the type of charcoal and the second is the type of sugarcane clone. The research was conducted on August 2017-February 2018. The combination of rice husk treatment and Bululawang sugarcane clover could increase the yield of vegetative growth of sugarcane. Bululawang which is applied with rice husk charcoal can improve vegetative growth and sugarcane clon PS 882 which is applied with charcoal wood can increase the absorption of Silica (Si). Rice husk charcoal can increase stem diameter and Si stem content at the age of 140.
\end{abstract}

Keywords: charcoal; amendments; sugarcane; silica (Si)

\section{INTISARI}

Tanaman tebu (Saccharum officinarum L.) merupakan salah satu komoditas utama di Indonesia yang merupakan tanaman yang menghasilkan gula. Produksi gula nasional mengalami penurunan karena produktivitas tanaman tebu yang rendah. Pemberian bahan yang ditujukan untuk memperbaiki kondisi tanah baik fisika, kimia maupun biologi disebut amandemen (ameliorasi). Bahan alam yang dapat digunakan untuk mengatasi defisiensi hara dan meningkatkan efisiensi pemupukan yaitu dengan pemberian arang. Tanaman tebu sangat membutuhkan unsur $\mathrm{Si}$ dalam 
pertumbuhannya. Salah satu bahan organik yang mengandung Si tinggi yaitu arang. Kandungan Si dari berbagai sumber berbeda-beda, Si pada arang sekam padi merupakan yang tertinggi. Selain faktor pemupukan, faktor klon yang sesuai dengan lahan juga sangat penting untuk meningkatkan produksi tebu. klon merupakan suatu langkah yang ditempuh untuk memberbaiki sifat suatu tanaman baik dari segi kualitatif dan kuantitatif. Penelitian ini bertujuan untuk menentukan kombinasi antara jenis arang dengan klon yang memiliki hasil pertumbuhan dan serapan hara paling baik. Penelitain dilakukan di lahan PT. Perkebunan Nusantara X Jengkol Kediri menggunakan Rancangan Acak Kelompok Lengkap (RAKL) dengan dua faktor. Faktor pertama yaitu jenis arang dan yang kedua yaitu jenis klon tebu. Penelitian dilakukan pada bulan Agustus 2017-Februari 2018. Kombinasi perlakuan arang sekam padi dan klon tebu Bululawang mampu meningkatkan hasil pertumbuhan vegetatif tanaman tebu. Tebu klon Bululawang yang diaplikasikan dengan arang sekam padi mampu memperbaiki pertumbuhan vegetatif dan tebu Klon PS 882 yang diaplikasikan dengan arang kayu mampu meningkatkan serapan unsur Silika (Si). Arang sekam padi mampu meningkatkan diameter batang dan kandungan Si jaringan batang pada umur 140 hspt.

Kata kunci: arang; amandemen; tebu; silika (Si)

\section{PENDAHULUAN}

Tanaman tebu (Saccharum officinarum L.) merupakan salah satu komoditas utama di Indonesia yang merupakan tanaman yang menghasilkan gula. Gula merupakan salah satu kebutuhan primer bagi masyarakat Indonesia yang hampir setiap hari dikonsumsi. Anonim (2015) menyebutkan bahwa, pada tahun 2014 produksi gula nasional sebesar 2.57 juta ton, sedangkan menurut Anonim (2016) mengatakan pada tahun 2015 produksi gula nasional sebesar 2.49 juta ton. Pada prinsipnya, peningkatan produksi gula dapat dilaksanakan melalui perluasan areal tanaman, peningkatan bobot tebu per hektar, dan peningkatan rendemen. Penurunan produktivitas tebu antara lain disebabkan oleh lahan yang tidak sesuai dengan syarat tumbuh dari tanaman tebu. Tebu harus dikembangkan pada lahan kering yang sesuai dengan syarat tumbuhnya karena kesesuaian lahan berkaitan erat dengan peningkatan produk agar peningkatan produksi dan hasil yang maksimal (Susilowati, 2008).

Kesuburan tanah berkaitan dengan hal pemupukan atau penambahan bahan yang dapat meningkatkan ketersediaan unsur hara di dalam tanah. Menurut Thompson and Troeh (1978) menyatakan bahwa, pemupukan yang tepat dan benar dapat mempercepat dan memperkuat pertumbuhan serta perkembangan tanaman, menambah daya tahan terhadap hama dan penyakit tertentu, maupun meningkatkan kualitas dan kuantitas hasil pertanian. Pengaplikasian pupuk kimia secara terusmenerus tanpa diimbangi dengan penambahan bahan organik akan membuat tanah 
Siswanto et al. / Vegetalika. 2019. 8(3): 192-201

menjadi keras dan menurunkan aktivitas mikroorganisme di dalam tanah. Bahan alam yang dapat digunakan untuk mengatasi defisiensi hara dan meningkatkan efisiensi pemupukan yaitu dengan pemberian arang (charcoal). Arang merupakan jenis-jenis bahan organik yang berasal dari berbagai sumber. Sumber dan komposisi bahan yang berbeda akan menyebabkan kemampuan mempengaruhi penyediaan hara pada tanah yang berbeda pula (Soemeinaboedhy dan Tejowulan, 2007).

Di antara banyak faktor yang mempengaruhi hasil panen, yang paling penting adalah potensi kultivar, kesuburan tanah, kondisi iklim, kejadian hama dan penyakit dan praktek budidaya. Nitrogen misalnya, bila diterapkan lebih di tanah berpasir dan pada kondisi curah hujan tinggi, dapat dengan mudah hilang oleh pencucian, mencemari air tanah dan mata air (Biggs et al., 2013). Di sisi lain, setiap kultivar tebu berbeda pada penyerapan dan penggunaan zat hara di tanah (Rengel and Damon, 2008). Dengan demikian, perlu untuk memilih kultivar yang efisien dalam penggunaan nutrisi, mengurangi risiko kontaminasi lingkungan dan mengurangi biaya produksi.

\section{BAHAN DAN METODE PENELITIAN}

Peneltian dilaksanakan pada bulan Agustus 2017 hingga Februari 2018 di lahan Pusat Penelitian Gula (PT. Perkebunan Nusantara X) Jengkol Kediri, Jawa Timur. Kegiatan penelitian di lahan meliputi pengolahan lahan, persiapan bahan tanam, penanaman, perawatan dan pengamatan pertumbuhan atau agronomis dari tanaman sampel sedangkan kegiatan di laboratorium yaitu pengamatan analisis tanah dan pengamatan tanaman korban. Alat yang digunakan 288 polibag dengan ukuran 35 cm x $35 \mathrm{~cm}$ cangkul, gathul, penggaris, alat tulis, gelas ukur, buret, pengaduk analitik, erlenmeyer, tabung reaksi, pipet ukur, gelas piala, pemanas listrik/hot plate, eksikator, tanur listrik $1000^{\circ} \mathrm{C}$, timbangan analitik dengan kapasitas maksimal 450 gram dan tingkat ketelitian 0,05 gram, tabung digestion dan blok digestion, alat destilasi, lumpang porselen, oven, shaker/pengaduk sampel tanah, kertas saringan tanah, labu ukur kamera digital, pH meter portabel (HI 9182, Hanna Instrumens, Ldt.), Spektrofotometer UV-Vis (UV-1700, 230VCE), cawan platina, pemanas listrik, tanur listrik dan AAS (Atomic Absorption Spectroscopy). Bahan yang digunakan yaitu bibit dari tiga klon tebu yaitu PS.881, Bululawang dan PS.882, pupuk kompos, pupuk NPK, arang kayu, arang sekam padi, arang seresah. Asam sulfat pekat, kalium dikromat $1 \mathrm{~N}$, glukosa, $\mathrm{CuSO}_{4}$ anhidrat, $\mathrm{Na}_{2} \mathrm{SO}_{4}$ anhidrat, asam borat, asam asetat, $\mathrm{HF}$ pekat, $\mathrm{H}_{2} \mathrm{SO}_{4}$ pekat asam nitrat $65 \%$, asam perklorida 60\%, Natrium hidroksida ( $\mathrm{NaOH})$, Na-asetat, Asam klorida 
( $\mathrm{HCl}) 37 \%$, indikator Conway, batu didih, pupuk nitrogen (urea), pupuk fosfor (SP-36) dan pupuk $\mathrm{K}(\mathrm{KCl})$.

Penelitian ini menggunakan Rancangan Acak Kelompok Lengkap (RAKL) dengan dua faktor dan tiga blok sebagai ulangan. Faktor pertama adalah jenis arang yang diaplikasikan, yaitu : arang kayu, arang sekam dan arang seresah tebu. Faktor yang kedua yaitu jenis klon tebu yang digunakan yaitu: PS.881 (klon 1), PS.882 (klon 2) dan Bululawang (klon 3). Data yang diperoleh diuji beda nyata perlakuannya dengan menggunakan sidik ragam (anova). Apabila pada sidik ragam perlakuan menunjukkan pengaruh nyata pada taraf $5 \%$, maka untuk mengetahui perbedaan antar perlakuan perlu dianalisis lagi dengan uji beda nyata jujur Duncan dengan taraf nyata $5 \%$. Analisis data dikerjakan menggunakan perangkat lunak SAS. Visualisasi data dikerjakan dengan menggunakan bantuan perangkat lunak Microsoft Excel 2013. Taraf kepercayaan yang digunakan yaitu 95\% untuk menyatakan ada perbedaan yang signifikan.

\section{HASIL DAN PEMBAHASAN}

Jumlah anakan merupakan salah satu parameter penting dalam pertumbuhan awal tanaman tebu. Jumlah anakan akan berpengaruh terhadap berat segar batang dan berat kering pada tanaman tebu. Jumlah anakan akan bertambah seiring bertambahnya umur tanaman, namun akan berhenti pada fase tertentu. Pertumbuhan vegetatif pada tanaman tebu paling optimal yaitu pada umur 3-4 bulan.

Tabel 1. Pengaruh jenis arang dan klon terhadap jumlah anakan tebu 84 dan $112 \mathrm{hspt}$

\begin{tabular}{|c|c|c|}
\hline \multirow{3}{*}{$\begin{array}{l}\text { Perlakuan } \\
\text { Media Tanam: } \\
\text { - Kontrol }\end{array}$} & \multicolumn{2}{|c|}{ Jumlah Anakan } \\
\hline & & \\
\hline & $11.41 \mathrm{a}$ & $13.18 \mathrm{a}$ \\
\hline - $\quad$ Arang Sekam Padi & $13.14 \mathrm{a}$ & $14.40 \mathrm{a}$ \\
\hline - Arang Kayu & $11.14 \mathrm{a}$ & $13.07 \mathrm{a}$ \\
\hline - Arang Seresah & $11.48 \mathrm{a}$ & $13.25 \mathrm{a}$ \\
\hline \multicolumn{3}{|l|}{ Klon: } \\
\hline - PS 881 & $10.08 b$ & $12.55 b$ \\
\hline - PS 882 & $11.02 b$ & $13.06 \mathrm{~b}$ \\
\hline _ Bululawang & $14.27 \mathrm{a}$ & $14.86 \mathrm{a}$ \\
\hline Interaksi & $(-)$ & $(-)$ \\
\hline
\end{tabular}

Berdasarkan Tabel 1 menunjukkan bahwa jumlah anakan tanaman tebu pada umur 84 dan 112 hspt tidak terdapat interaksi antara kombinasi jenis klon dengan jenis 
Siswanto et al. / Vegetalika. 2019. 8(3): 192-201

arang. Pada perlakuan jenis klon terdapat beda nyata, sedangkan pada perlakuan jenis arang tidak ada beda nyata. Dalam hal ini pengaruh genetik dari klon lebih berpengaruh terhadap jumlah anakan daripada jenis arang yang diaplikasikan. Menurut Insan (2010), semakin cepat mata tunas tumbuh dan perkembangan akarnya baik, dapat meningkatkan jumlah anakan tebu yang dihasilkannya. Pada perlakuan media tanam meskipun tidak terjadi beda nyata, hasil dengan pemberian jenis arang sekam padi menunjukkan hasil yang lebih tinggi dibandingkan dengan arang lainnya.

Arang sekam padi bisa disebut sebagai sumber pupuk silika alternatif, karena kandungan $\mathrm{Si}$ yang tinggi dibandingkan dengan arang yang digunakan dalam penelitian ini. Pemberian arang yang mengandung Si tinggi akan mempengaruhi kandungan $\mathrm{P}$ tersedia di dalam tanah. hal ini sejalan dengan pendapat Sanchez (1992), Si mampu meningkatkan $P$ tersedia tanah yang berperan penting dalam pertumbuhan batang dan akar tanaman. Selain parameter jumlah anakan, parameter diameter batang tebu juga sangat penting untuk diketahui. Diameter batang merupakan parameter yang dapat digunakan untuk mengetahui produksi tanaman tebu.

Tabel 2. Pengaruh jenis arang dan klon terhadap diameter batang tebu 98 dan $140 \mathrm{hspt}$

\begin{tabular}{llcc}
\hline & Jenis Arang + Klon & $98 \mathrm{Hspt}$ & $140 \mathrm{Hspt}$ \\
\hline \multirow{2}{*}{ Kontrol } & PS 881 & $26.36 \mathrm{~b}$ & $36.08 \mathrm{~b}$ \\
& PS 882 & $11.59 \mathrm{~g}$ & $19.56 \mathrm{~h}$ \\
\multirow{4}{*}{ Arang Sekam Padi } & Bululawang & $23.69 \mathrm{~d}$ & $32.87 \mathrm{de}$ \\
& PS 881 & $23.62 \mathrm{~d}$ & $32.40 \mathrm{de}$ \\
\multirow{2}{*}{ Arang Kayu } & PS 882 & $13.44 \mathrm{f}$ & $21.58 \mathrm{~g}$ \\
& Bululawang & $31.30 \mathrm{a}$ & $42.02 \mathrm{a}$ \\
& PS 881 & $21.40 \mathrm{e}$ & $29.44 \mathrm{f}$ \\
Arang Seresah & PS 882 & $24.73 \mathrm{c}$ & $33.54 \mathrm{de}$ \\
& Bululawang & $24.61 \mathrm{c}$ & $34.16 \mathrm{~cd}$ \\
& PS 881 & $24.67 \mathrm{c}$ & $33.45 \mathrm{de}$ \\
Interaksi & PS 882 & $23.09 \mathrm{~d}$ & $31.97 \mathrm{e}$ \\
\hline CV\% & Bululawang & $25.81 \mathrm{~b}$ & $35.35 \mathrm{~cd}$ \\
\hline Ker & & $(+)$ & $(+)$ \\
\hline
\end{tabular}

Keterangan: $(+)$ ada interaksi, angka rerata yang diikuti huruf yang sama menunjukkan tidak adanya beda nyata pada uji Duncan Multiple Range Test pada taraf 5\%.

Tabel 2 menunjukkan adanya interaksi pada perlakuan arang sekam padi dengan klon tebu Bululawang. Pada umur 98 dan 140 hspt memberikan hasil pengamatan diameter batang sebesar 31.30 dan $42.02 \mathrm{~mm}$. Diameter batang akan selalu membesar seiring bertambahnya umur dan tinggi tanaman tebu. Komposisi arang sekam yang didominasi unsur Si yang cukup tinggi akan memberikan pengaruh yang cukup besar terhadap pertumbuhan tanaman tebu. Si mampu meningkatkan $P$ 
tersedia tanah yang berperan penting dalam pertumbuhan batang dan akar tanaman. Fosfor dibutuhkan tanaman untuk pembentukan sel pada jaringan yang sedang tumbuh termasuk batang (Gardner et al., 1991). Semakin baik pertumbuhan akar, maka kemampuan akar dalam menjangkau pasokan nutrisi tanaman akan semakin baik dan kebutuhan tanaman menjadi terpenuhi sehingga pertumbuhannya akan optimal.

Tabel 3. Pengaruh jenis arang dan klon terhadap berat segar batang tebu 84 dan $140 \mathrm{hspt}$

\begin{tabular}{lcc}
\hline \multirow{2}{*}{ Perlakuan } & \multicolumn{2}{c}{ Berat Segar Batang (g) } \\
\cline { 2 - 3 } Media Tanam: & $84 \mathrm{hspt}$ & $140 \mathrm{hspt}$ \\
$-\quad$ Kontrol & $9.77 \mathrm{a}$ & $25.33 \mathrm{~b}$ \\
$-\quad$ Arang Sekam Padi & $11.68 \mathrm{a}$ & $34.86 \mathrm{a}$ \\
$-\quad$ Arang Kayu & $11.37 \mathrm{a}$ & $35.70 \mathrm{a}$ \\
$-\quad$ Arang Seresah & $11.68 \mathrm{a}$ & $35.79 \mathrm{a}$ \\
\hline Klon: & $9.86 \mathrm{~b}$ & $32.43 \mathrm{a}$ \\
$-\quad$ PS 881 & $9.77 \mathrm{~b}$ & $32.88 \mathrm{a}$ \\
$-\quad$ PS 882 & $13.72 \mathrm{a}$ & $33.45 \mathrm{a}$ \\
- Bululawang & $(-)$ & $(-)$ \\
\hline Interaksi & \multicolumn{2}{c}{}
\end{tabular}

Berat segar batang merupakan salah satu parameter yang sering digunakan untuk mempelajari pertumbuhan tanaman. Bobot segar batang adalah bobot tanaman setelah dipanen sebelum tanaman tersebut layu dan kehilangan air. Tabel.3 menunjukkan bahwa hasil berat segar batang tidak terdapat interaksi antar perlakuan jenis arang dan jenis klon. Berat segar batang berkaitan dengan jumlah air yang terkandung pada batang. Bobot segar batang juga merupakan gambaran dari fotosintesis selama tanaman melakukan proses pertumbuhan, $90 \%$ dari berat kering tanaman merupakan hasil dari fotosintesis. Syekfani (2000) menyatakan bahwa dengan pemberian pupuk organik, unsur hara yang tersedia dapat diserap tanaman dengan baik karena itulah pertumbuhan daun lebih lebar dan fotosintesis terjadi lebih banyak. 
Siswanto et al. / Vegetalika. 2019. 8(3): 192-201

Tabel 4. Pengaruh jenis arang dan klon terhadap berat kering batang $84 \mathrm{hspt}$

\begin{tabular}{lcccc}
\hline \multirow{2}{*}{ Media Tanam } & \multicolumn{3}{c}{ Berat Kering Batang (g) Umur 84 hspt } & \multirow{2}{*}{ Rerata } \\
\cline { 2 - 4 } & \multicolumn{3}{c}{ Klon } \\
\cline { 2 - 4 } & PS 881 & PS 882 & Bululawang & \\
\hline Kontrol & $3.89 \mathrm{bcd}$ & $3.10 \mathrm{~d}$ & $5.33 \mathrm{abc}$ & 4.11 \\
Arang Sekam Padi & $4.12 \mathrm{a}-\mathrm{d}$ & $4.02 \mathrm{bcd}$ & $5.64 \mathrm{ab}$ & 4.59 \\
Arang Kayu & $3.47 \mathrm{~cd}$ & $5.93 \mathrm{a}$ & $4.66 \mathrm{a}-\mathrm{d}$ & 4.68 \\
Arang Seresah & $3.91 \mathrm{bcd}$ & $3.25 \mathrm{~d}$ & $5.23 \mathrm{abc}$ & 4.13 \\
\hline Rerata & 3.85 & 4.07 & 5.21 & $(+)$ \\
\hline CV\% & \multicolumn{4}{c}{22.46} \\
\hline \multicolumn{2}{l}{ Keterangan: (+) ada interaksi, angka rerata yang diikuti huruf yang sama menunjukkan tidak } \\
\multicolumn{1}{r}{ adanya beda nyata pada uji Duncan Multiple Range Test pada taraf 5\%. }
\end{tabular}

Pada Tabel.4 menunjukkan adanya interaksi antar perlakuan pada umur tanaman 84 hspt. Kombinasi perlakuan arang kayu dengan jenis klon tebu PS 882 memberikan hasil tertinggi. Batang merupakan komponen hasil utama pada tanaman tebu, karena pada batamg terdapat kandungan nira yang tertinggi. Pengaplikasian bahan organik seperti arang tentunya akan memperbaiki struktur tanah, sehingga perkembangan akar bagus dan berpengaruh terhadap hasil tanaman tebu. Imanuddin et al., (2005), menyatakan bahwa pemberian $10 \%$ arang dapat meningkatkan pertumbuhan tinggi dan diameter. Arang kayu yang digunakan pada penelitian ini menggunakan jenis kayu sengon. Pertumbuhan batang berkaitan dengan unsur $\mathrm{K}$. Pengaplikasian arang tidak mempengaruhi kadar $\mathrm{N}$ total, namun kandungan $\mathrm{K}$ meningkat (Komarayati et al., 2013).

Tabel 5. Kandungan Si pada jaringan batang dengan aplikasi jenis arang dan klon $140 \mathrm{hspt}$

\begin{tabular}{lcc}
\hline & Jenis Arang + Klon & Si Batang (\%) \\
\hline \multirow{2}{*}{ Kontrol } & PS 881 & $0.74 \mathrm{cde}$ \\
& PS 882 & $0.55 \mathrm{de}$ \\
\multirow{3}{*}{ Arang Sekam Padi } & Bululawang & $0.44 \mathrm{e}$ \\
& PS 881 & $0.95 \mathrm{bcd}$ \\
\multirow{2}{*}{ Arang Kayu } & PS 882 & $0.95 \mathrm{bcd}$ \\
& Bululawang & $1.83 \mathrm{a}$ \\
\multirow{4}{*}{ Arang Seresah } & PS 881 & $0.81 \mathrm{~b}-\mathrm{e}$ \\
& PS 882 & $1.19 \mathrm{~b}$ \\
& Bululawang & $0.85 \mathrm{bcd}$ \\
& PS 881 & $0.95 \mathrm{bcd}$ \\
& PS 882 & $1.00 \mathrm{bc}$ \\
& Bululawang & $0.93 \mathrm{bcd}$ \\
\hline
\end{tabular}

Keterangan: (+) ada interaksi, angka rerata yang diikuti huruf yang sama menunjukkan tidak adanya beda nyata pada uji Duncan Multiple Range Test pada taraf 5\%. 
Siswanto et al. / Vegetalika. 2019. 8(3): 192-201

Tabel 6. Serapan silika (Si) jaringan tanaman tebu $140 \mathrm{hspt}$

\begin{tabular}{lccc}
\hline \multirow{2}{*}{ Perlakuan Media } & \multicolumn{3}{c}{ Serapan Si Jaringan Tanaman (g/bagian tanaman) } \\
\cline { 2 - 4 } & Akar & Batang & Daun \\
\hline Kontrol & $0.74 \mathrm{~b}$ & $0.87 \mathrm{~b}$ & $0.47 \mathrm{~b}$ \\
Arang Sekam Padi & $1.34 \mathrm{a}$ & $1.82 \mathrm{a}$ & $0.80 \mathrm{a}$ \\
Arang Kayu & $1.11 \mathrm{ab}$ & $1.86 \mathrm{a}$ & $0.89 \mathrm{a}$ \\
Arang Seresah & $1.01 \mathrm{ab}$ & $1.85 \mathrm{a}$ & $0.47 \mathrm{ab}$ \\
\hline Perlakuan Klon & & $0.69 \mathrm{p}$ \\
Ps 881 & $0.92 \mathrm{p}$ & $1.69 \mathrm{p}$ & $0.77 \mathrm{p}$ \\
Ps 882 & $1.18 \mathrm{p}$ & $1.58 \mathrm{p}$ & $0.68 \mathrm{p}$ \\
Bululawang & $1.04 \mathrm{p}$ & $1.69 \mathrm{p}$ & $(-)$ \\
\hline \multicolumn{1}{c}{ Interaksi } & $(-)$ & $(-)$ & \\
\hline Keterangan: (-) menunjukkan tidak ada interaksi, angka rerata yang diikuti huruf yang sama \\
\multicolumn{1}{c}{ menunjukkan tidak adanya beda nyata pada uji Duncan Multiple Range Test pada } \\
\multicolumn{2}{c}{ taraf 5\%. }
\end{tabular}

Tabel 5 merupakan hasil analisa Si jaringan tanaman pada bagian batang tebu. Hasil di atas menunjukkan adanya interaksi antar perlakuan. Kombinasi perlakuan arang sekam padi dengan klon bululawang memberikan hasil Si paling tinggi yaitu sebesar $1.83 \%$. Batang merupakan bagian tebu yang paling penting, karena kandungan sukrosanya yang tinggi. Menurut Marschner (2012) menyatakan bahwa unsur silika memberikan dampak terhadap batang tebu yaitu dapat meningkatkan ketebalan dinding sel batang yang meyebabkan tanaman tebu lebih tegak dan lebih tahan rebah. Pikukuh et al., (2015) mengindikasikan beberapa pengaruh Si terhadap tanaman tebu ialah semakin panjang tanaman tebu maka semakin besar diameter batang tanaman tebu dan juga meningkatnya jumlah sogolan.

Tabel 6 menunjukkan hasil analisa serapan Si jaringan tanaman di bagian akar, batang, dan daun pada umu tanaman 140 hspt. Hasil pada Tabel 6 menunjukkan bahwa tiadak ada interaksi antar perlakuan. Pada perlakuan jenis arang terdapat beda nyata pada masing-masing jaringan tanaman. Pada perlakuan jenis klon tidak ada beda nyata. Pada perlakuan jenis arang di jaringan akar, aplikasi arang sekam padi memiliki nilai serapan silika yang paling baik yaitu sebesar $1.34 \mathrm{~g} / \mathrm{bagian}$ tanaman. Pada jaringan batang, aplikasi tiga jenis arang mampu meningkatkan serapan silika dibandingkan kontrol. Hasil serapan dengan aplikasi arang sekam padi memiliki hasil yang cenderung lebih tinggi. Pada jaringan daun pemberian arang sekam padi dan kayu memberikan hasil lebih baik.

Aplikasi arang kayu cenderung lebih tinggi hasil serapannya yaitu sebesar 0,89 $\mathrm{g} /$ bagian tanaman. Meningkatnya hasil serapan hara dengan aplikasi arang diduga karena mampu memperbaiki dan mengoptimalkan pertumbuhan. Warnock et al. (2007) 
Siswanto et al. / Vegetalika. 2019. 8(3): 192-201

menyatakan bahwa arang mampu menyerap unsur hara dan air sehingga unsur hara dapat tersedia bagi tanaman. Pertumbuhan yang optimal dengan aplikasi arang ini juga karena meningkatnya bahan organik tanah. Hal ini sesuai dengan Steiner et al. (2007) menyatakan bahwa aktivitas mikroba akan meningkat di dalam tanah sehingga berpengaruh terhadap bahan organik tanah. Dalam hal serapan hara aplikasi arang mampu memperbaiki serapan hara oleh tanaman. Perlakuan pemberian arang akan mampu meningkatkan kapasitas menahan air maupun menyediakan unsur hara serta memperbaiki serapan hara oleh tanaman (Lehmann and Joseph, 2009).

\section{KESIMPULAN}

1. Kombinasi perlakuan arang sekam padi dan klon tebu Bululawang mampu meningkatkan hasil pertumbuhan vegetatif tanaman tebu.

2. Tebu klon Bululawang yang diaplikasikan dengan arang sekam padi mampu memperbaiki pertumbuhan vegetatif dan tebu Klon PS 882 yang diaplikasikan dengan arang kayu mampu meningkatkan serapan unsur Silika (Si).

3. Arang sekam padi mampu meningkatkan diameter batang dan kandungan Si jaringan batang pada umur $140 \mathrm{hspt}$.

\section{DAFTAR PUSTAKA}

Anonim. 2015. Produksi perkebunan besar menurut jenis tanaman, Indonesia (ton), 1995-2014*. Diakses pada 22 April 2017.

Anonim. 2016. AGl: Produksi gula tahun 2016 sebanyak 2,3 juta ton. http://www.agrofarm.co.id/m/perkebunan/2570/agi-produksi-gula-tahun-2016 sebanyak- 23- juta-ton/\#.V-TcblkWnvl>. Diakses pada 02 Mei 2017.

Biggs, J., Thorburn, P., Crimp, S., Masters, B. and Attard, S. 2013. Interactions between climate change and sugarcane management systems for improving water quality leaving farms in the Mackay Whitsunday Region, Australia. Agriculture, Ecosystems \& Environment 180: 79-89.

Gardner,F. P, Pearce, R. B, and Mitchell, R. L. 1991. Physiology of crop plants. Jakarta. Universitas Indonesia Press.

Imanuddin, R., Siregar, C.A. and Nobuo, I. 2005. Growth of Shorea leprosula and Shorea macrophylla plantation as affected by charcoal application in West Kalimantan. Proceeding of the 2nd workshop on demonstration study on carbon fixing forest management in Indonesia. Kerjasama FORDA dan JICA.

Insan, H. 2010. Perbandingan pertumbuhan tanaman tebu (Saccharum officinarum L.) dari bibit yang berasal dari kebun bibit datar dengan kebun tebu giling. Jurnal Agronomi dan Hortikultura. Fakultas Pertanian Institut Pertanian Bogor. Bogor. 
Komarayati, S., Gusmailina dan G. Pari. 2013. Arang dan cuka kayu: Produk hasil hutan bukan kayu untuk meningkatkan pertumbuhan tanaman dan serapan hara karbon. Jurnal Penelitian Hasil Hutan. 1: 49-62.

Lehmann, J. And S. Joseph. 2009. Biochar for environmental management. Earthscan: 127-143. UK.

Marschner, P. 2012. Mineral nutrition of higher plants. 3rd Edition. Academic Press, New York.

Pikukuh, P., Djajadi , S. Y. Tyasmoro dan N. Aini. 2015. Pengaruh frekuensi dan konsentrasi penyemprotan pupuk nano silika (Si) terhadap pertumbuhan tanaman tebu (Saccharum officinarum L.). Jurnal Produksi Tanaman. 3: 249 258.

Rengel, Z. and Damon, P. M. 2008. Crops and genotypes differ in efficiency of potassium uptake and use. Physiologia Plantarum 133: 624-636.

Sanchez, P. A. 1992. Sifat dan Pengelolaan Tanah Tropika 1. ITB, Bogor.

Soemeinaboedhy, I. N. dan R. S. Tejowulan. 2007. Pemanfaatan berbagai macam arang sebagai sumber hara $\mathrm{P}$ dan $\mathrm{K}$ serta sebagai pembenah tanah. Agroteksos 17: 114-122.

Steiner, C., W.G. Teixeria, J. Lehmann, T. Nehls, J.L.V, de Macedo, W.E.H. Blum, and W. Zech. 2007. Long term effects of manure, charcoal, and mineral fertilization on crop production and fertility on a highly weathered Central Amazonian upland soil. Plant and Soil. 291: 275-290.

Susilowati. 2008. Kesesuaian lahan untuk tanaman tebu. Universitas Muhammadiyah, Surakarta.

Syekhfani. 2000. Arti penting bahan organik bagi kesuburan tanah. Jurnal Penelitian Pupuk Organik.

Thompson, L.M., and F.R. Troeh. 1978. Soil and soil fertility. Mc graw-Hill Book.Co. New York.

Warnock, D.D., J. Lehmann, T.W. Kuyper, and M.C. Rillig. 2007. Mycorhizal responses to biochar in soil-concepts and mechanisms. Plant and Soil. 300: 9-20. 